\title{
Robust Control Design for a Benchmark Problem
}

$\mathbf{I}^{\mathrm{T}}$ $\mathrm{T}$ is quite possible that twenty years from now controls researchers will look back at our era as a "golden age" of control theory development. The scope and pace of current developments have reached a level beyond even the tremendous strides of the 1960s and 1970s. This special section of the JGCD, which is devoted to the treatment of a benchmark problem, clearly demonstrates the extent of ongoing activity.

As we passed, in approximately 1960, from the "classical" era to the "modern" era in feedback control, the research pendulum seemed to swing irretrievably to the state-space side of the subject. Yet the replacement of Nyquist plots with Riccati equations was to be only the first act in a drama with many subplots and unexpected twists: LQR, LQG, QFT, LQG/ LTR, guaranteed cost control, $H_{\infty}, \mu$, and, now, state-space $H_{\infty}$. The pace of such developments continues unabated.

The intent of this issue is to provide a glimpse of a broad spectrum of this activity. Specifically, each of the papers focuses on the same problem, namely, a two-mass system with uncertain spring constant and noncollocated sensor and actuator. In spite of its simplicity, the problem is nontrivial in that it captures both rigid body mode and flexible body mode with uncertainty. This benchmark problem has been examined in more than 45 journal and conference papers. Although it would have been easy to pose more involved extensions of this problem for this section, transparency of the problem and comparison of the various techniques would have been lost.
Besides addressing the benchmark problem, each paper provides a brief description of the technical approach. It is hoped that this combination of theoretical overview and illustrative example will be useful both to students and researchers. The section begins with an introductory paper by Wie and Bernstein, followed by a paper by Stengel and Marrison that provides a detailed comparison of a collection of earlier designs for the benchmark problem. A variety of techniques are represented by six papers, namely, minimax method (Mills and Bryson), game theoretic control (Rhee and Speyer), pole placement (Lilja and Astrom), quantitative feedback theory (Jayasuriya et al.), maximum entropy (Collins et al.), and $\mu$ synthesis (Braatz and Morari). These papers are then followed by five papers on a variety of techniques based on state-space $H_{\infty}$ theory (Chiang and Safonov; Byrns and Calise; Wang et al.; Adams and Banda; and Wie et al.).

Besides the authors themselves, the success of this section is due to Bong Wie of Arizona State University and Dennis S. Bernstein of the University of Michigan. I'd like to express my appreciation for their efforts in making this unusual and valuable issue a reality. Their accomplishment continues to teach us that in spite of of the advances of the past, our knowledge is but a starting point for our future endeavors.

\section{K. Terry Alfriend Editor-in-Chief}

\section{Benchmark Problems for Robust Control Design}

\author{
Bong Wie* \\ Arizona State University, Tempe, Arizona 85287 \\ and \\ Dennis S. Bernstein $\dagger$ \\ University of Michigan, Ann Arbor, Michigan 48109
}

\section{Introduction}

$\mathbf{S}$ IMPLE, yet meaningful, control problems to highlight issues in robust control design and to provide a forum for the application of a variety of robust control design methodologies are formulated in this paper. Such problems have been studied by several researchers under a variety of assumptions. ${ }^{1-9}$ More recently, these problems were refined and addressed as benchmark problems for robust control design at the 1990 American Control Conference, ${ }^{10-16}$ the 1991 American Control Conference, ${ }^{17-28}$ and the 1992 American Control Conference. ${ }^{29-44}$

The papers in this special section of the Journal of Guidance, Control, and Dynamics are concerned with the original three problems of Ref. 10 , which address primarily a disturbance rejection control problem in the presence of parametric uncertainty. These problems are augmented with a new problem, called problem 4 , which is concerned with a command tracking control problem in the presence of plant modeling uncertainty. ${ }^{29}$ For problem 4 , control input saturation limit is

Copyright (C) 1992 by the American Institute of Aeronautics and Astronautics, Inc. All rights reserved.

*Professor, Department of Mechanical and Aerospace Engineering. Associate Fellow AIAA.

$\dagger$ Associate Professor, Department of Aerospace Engineering. specified explicitly. The previous problems 1,2 , and 3 are refined in Ref. 29; however, they are essentially the same as those presented in Ref. 10.

It is emphasized that in our problem statement certain aspects, such as parameter uncertainty with given nominal parameter values and nominal desired performance, are specified concretely, while other aspects, such as the sensor noise model, definition of settling time, measure of control effort, controller complexity, bandwidth, etc., are deliberately left vague. Each designer is thus given the opportunity to emphasize additional design tradeoffs for a realistic control design as desired.

\section{Benchmark Problems}

Consider the two-mass-spring system shown in Fig. 1, which is a generic model of an uncertain dynamical system with a rigid-body mode and one vibration mode.

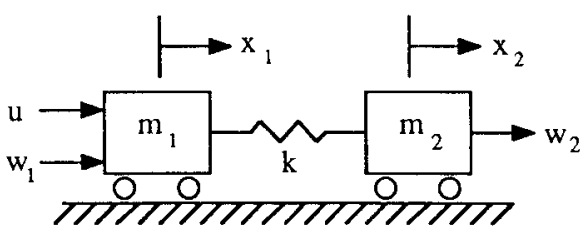

Fig. 1 Two-mass-spring system with uncertain parameters. 
It is assumed that for the nominal system $m_{1}=m_{2}=1$ and $k=1$ with appropriate units and time is in units of seconds. A control force acts on body 1 , and the position of body 2 is measured, resulting in a noncollocated actuator/sensor control problem.

This system can be represented in state-space form as

$$
\begin{gathered}
{\left[\begin{array}{l}
\dot{x}_{1} \\
\dot{x}_{2} \\
\dot{x}_{3} \\
\dot{x}_{4}
\end{array}\right]=\left[\begin{array}{cccc}
0 & 0 & 1 & 0 \\
0 & 0 & 0 & 1 \\
-k / m_{1} & k / m_{1} & 0 & 0 \\
k / m_{2} & -k / m_{2} & 0 & 0
\end{array}\right]\left[\begin{array}{l}
x_{1} \\
x_{2} \\
x_{3} \\
x_{4}
\end{array}\right]} \\
+\left[\begin{array}{c}
0 \\
0 \\
1 / m_{1} \\
0
\end{array}\right]\left(u+w_{1}\right)+\left[\begin{array}{c}
0 \\
0 \\
0 \\
1 / m_{2}
\end{array}\right] w_{2} \\
y=x_{2}+v \\
z=x_{2}
\end{gathered}
$$

where $x_{1}$ and $x_{2}$ are the positions of body 1 and body 2 , respectively; $x_{3}$ and $x_{4}$ the velocities of body 1 and body 2 , respectively; $u$ the control input acting on body $1 ; y$ the sensor output; $w_{1}$ and $w_{2}$ the plant disturbances acting on body 1 and body 2 , respectively; $v$ the sensor noise; and $z$ the output to be controlled (i.e., the performance variable).

\section{Problem 1} form

Design a constant-gain linear feedback controller of the

$$
\begin{gathered}
\dot{x}_{c}=A_{c} x_{c}+B_{c} y \\
u=C_{c} x_{c}+D_{c} y
\end{gathered}
$$

with the following properties:

1) For a unit impulse disturbance exerted on body 1 and/or body 2 , the controlled output $\left(z=x_{2}\right)$ has a settling time of about $15 \mathrm{~s}$ for the nominal system with $m_{1}=m_{2}=k=1$.

2) The closed-loop system is stable for $0.5 \leq k \leq 2.0$ and $m_{1}=m_{2}=1$

3) The closed-loop system is insensitive to high-frequency sensor noise.

4) Reasonable performance/stability robustness and reasonable gain/phase margins are achieved with reasonable bandwidth.

5) Reasonable control effort (e.g., peak control input) is used.

6) Reasonable controller complexity (e.g., controller order) is needed.

\section{Problem 2}

The same as problem 1 except in place of property 2 insert:

2) A stability robustness measure with respect to the three uncertain parameters $m_{1}, m_{2}$, and $k$ (with nominal values of $m_{1}=m_{2}=k=1$ ) is maximized.

\section{Problem 3}

The same as problem 1 except in place of property 1 insert:

1) For a sinusoidal disturbance with known frequency of $0.5 \mathrm{rad} / \mathrm{s}$ acting on body 1 and/or body 2 , but with unknown constant amplitude and phase, the closed-loop system achieves asymptotic disturbance rejection of the controlled output $z$ with approximately a 20 -s settling time for $m_{1}=m_{2}=1$ and $0.5 \leq k \leq 2.0$

\section{Problem 4}

Design a feedback/feedforward controller for a unit-step output command tracking problem for the controlled output $z$ with the following properties:

1) The control input is limited as $|u| \leq 1$.

2) Performance requirement: settling time and overshoot are both to be minimized.

3) Robustness requirement: performance robustness and stability robustness with respect to the three uncertain parameters $m_{1}, m_{2}$, and $k$ (with the nominal values of $m_{1}=m_{2}=k=1$ ) are both to be maximized.

4) If there are conflicts between properties 2 and 3, then performance vs robustness tradeoffs must be considered.

For each design (where applicable), please provide the following:

a) Controller matrices $\left(A_{c}, B_{c}, C_{c}\right.$, and $\left.D_{c}\right)$ and/or poles and zeros of compensators.

b) Gain and phase margins.

c) Time responses of $x_{1}, x_{2}$, and $u$ for the nominal system.

d) Evidence of ability to withstand sensor noise.

e) Evidence of performance/stability robustness (e.g., realparameter margin or $\mu$ ).

\section{Remark}

It is again emphasized that each designer is given the opportunity to consider additional design tradeoffs for a realistic control design by including the effects of unmodeled high-frequency dynamics, actuator/sensor dynamics, bandwidth limit, time delay, etc.

\section{References}

1 Bryson, A. E., Jr., "Some Connections Between Modern and Classical Control Concepts," ASME Journal of Dynamic Systems, Measurement, and Control, Vol. 101, June 1979, pp. 91-98.

${ }^{2}$ Hyland, D. C., and Madiwale, A. N., "A Stochastic Design Approach for Full-Order Compensation of Structural Systems with Uncertain Parameters," Proceedings of the AIAA Guidance, Navigation, and Control Conference, AIAA, New York, 1981, pp. 324-332.

${ }^{3}$ Ashkenazi, A., and Bryson, A. E., Jr., "Control Logic for Parameter Insensitivity and Disturbance Attenuation,"' Journal of Guidance, Control, and Dynamics, Vol. 5, No. 4, 1982, pp. 383-388.

${ }^{4}$ Bryson, A. E., Jr., Hermelin, S., and Sun, J., "LQG Controller Design for Robustness," 1986 American Control Conference (Seattle, WA), June 1986.

${ }^{5}$ Franklin, G. F., and Powell, J. D., Feedback Control of Dynamic Systems, Addison-Wesley, Reading, MA, 1986, pp. 450-473.

${ }^{6} \mathrm{Wie}, \mathrm{B}$. , and Byun, K.-W., "New Generalized Structural Filtering Concept for Active Vibration Control Synthesis,' Journal of Guidance, Control, and Dynamics, Vol. 12, No. 2, 1989, pp. 147-154.

${ }^{7}$ Byun, K.-W., Wie, B., and Sunkel, J., "Robust Non-MinimumPhase Compensation for a Class of Uncertain Dynamical Systems," Journal of Guidance, Control, and Dynamics, Vol. 14, No. 6, 1991, pp. 1191-1199.

${ }^{8}$ Wedell, E., Chuang, C.-H., and Wie, B., "Stability Robustness Margin Computation for Structured Real-Parameter Perturbations," Journal of Guidance, Control, and Dynamics, Vol. 14, No. 3, 1991, pp. 607-614.

${ }^{9}$ Bryson, A. E., Jr., and Carrier, A., "A Comparison of Control Synthesis Using Differential Games $\left(H_{\infty}\right)$ and LQR," Proceedings of the AIAA Guidance, Navigation, and Control Conference, AIAA, Washington, DC, 1989, pp. 1422-1427.

${ }^{10}$ Wie, B., and Bernstein, D., "A Benchmark Problem for Robust Control Design," Proceedings of the 1990 American Control Conference (San Diego, CA), May 1990, pp. 961-962; also, Proceedings of the 1991 American Control Conference (Boston, MA), June 1991, pp. $1929-1930$.

${ }^{11}$ Byrns, E. V., and Calise, A. J., "Fixed Order Dynamic Compensation for the $H_{2} / H_{\infty}$ Benchmark Problem," Proceedings of the 1990 American Control Conference (Boston, MA), May 1990, pp. 963-965.

${ }^{12}$ Chiang, R. Y., and Safonov, M. G., " $H_{\infty}$ Robust Control Synthesis for an Undamped, Non-Colocated Spring-Mass Systems," Proceedings of the 1990 American Control Conference (San Diego, CA), May 1990, pp. 966-967.

${ }^{13}$ Ly, U., "Robust Control Design Using Nonlinear Constrained Optimization," Proceedings of the 1990 American Control Conference (San Diego, CA), May 1990, pp. 968-969. 
${ }^{14}$ Collins, E. G., and Bernstein, D. S., "Robust Control Design for a Benchmark Problem," Proceedings of the 1990 American Control Conference (San Diego, CA), May 1990, pp. 970-971.

${ }^{15}$ Rhee, I., and Speyer, J., "Application of a Game Theoretic Controller to a Benchmark Problem," Proceedings of the 1990 American Control Conference (San Diego, CA), May 1990, pp. 971-972.

${ }^{16}$ Wie, B., Liu, Q., and Byun, K.-W., "Robust $H_{\infty}$ Control Synthesis Method and Its Application to a Benchmark Problem" 1990 American Control Conference (San Diego, CA), May 1990.

${ }^{17}$ Stengel, R., and Marrison, C., "Robustness of Solutions to a Benchmark Control Problem,"' Proceedings of the 1991 American Control Conference (Boston, MA), June 1991, pp. 1915-1916.

${ }^{18}$ Mills, R., and Bryson, A. E., Jr., "Minimax State Feedback Design with Norms on Initial Conditions, Disturbances, and Parameter Changes," Proceedings of the 1991 American Control Conference (Boston, MA), June 1991, pp. 1917-1918.

${ }^{19}$ Hagood, N., and Crawley, E., "The Application of Cost Averaging Techniques to Robust Control of the Benchmark Problem," Proceedings of the 1991 American Control Conference (Boston, MA), June 1991, pp. 1919-1920.

${ }^{20}$ Jayasuriya, S., Nwokah, O., and Yaniv, O., "The Benchmark Problem Solution by Quantitative Feedback Theory," Proceedings of the 1991 American Control Conference (Boston, MA), June 1991, pp. 1921-1922.

${ }^{21}$ Douglas, J., and Athans, M., "Robust LQR Control for the Benchmark Problem," Proceedings of the 1991 American Control Conference (Boston, MA), June 1991, pp. 1923-1924.

${ }^{22}$ Byrns, E., Jr., and Calise, A., "A Loop Transfer Recovery Approach to $H_{\infty}$ Design for the Coupled Mass Benchmark Problem," Proceedings of the 1991 American Control Conference (Boston, MA), June 1991, pp. 1925-1926.

${ }^{23}$ Chiang, R. Y., and Safonov, M. G., "Design of $H_{\infty}$ Controller for a Lightly Damped System Using a Pole Shifting Theorem," Proceedings of the 1991 American Control Conference (Boston, MA), June 1991, pp. 1927-1928.

${ }^{24}$ Lilja, M., and Astrom, K., "An Approximate Pole Placement Approach," Proceedings of the 1991 American Control Conference (Boston, MA), June 1991, pp. 1931-1932.

${ }^{25}$ Warren, W., and Wie, B., "Parameter Margins for Stabilized, Conservative 'Multilinear' Systems," Proceedings of the 1991 American Control Conference (Boston, MA), June 1991, pp. 1933-1934.

${ }^{26}$ Collins, E., Jr., and Bernstein, D., "Robust Control Design for the Benchmark Problem Using Maximum Entropy Design," Proceedings of the 1991 American Control Conference (Boston, MA), June 1991, pp. 1935-1936.

${ }^{27}$ Hollot, C., and Djaferis, T., "Using Non-Parametric Representations to Model the Parametric Uncertainty in a Benchmark Problem," 1991 American Control Conference (Boston, MA), June 1991.

${ }^{28}$ Balas, G., and Packard, A., "Robust Control Design for the Benchmark Problem Using the Structured Singular Value," 1991 American Control Conference (Boston, MA), June 1991.

${ }^{29} \mathrm{Wie}, \mathrm{B}$., and Bernstein, D., "Benchmark Problems for Robust Control Design (1992 ACC version)," Proceedings of the 1992 Amer- ican Control Conference (Chicago, IL), June 1992, pp. 2047-2048.

${ }^{30}$ Adams, R. J., and Banda, S., "An $\mathrm{H}_{\infty}$ Constrained Robust $\mathrm{H}_{2}$ Solution for a Benchmark Problem," Proceedings of the 1992 American Control Conference (Chicago, IL), June 1992, pp. 2049-2052.

${ }^{31}$ Friedland, B., "An Observer-Based Design of a Controller for Spring-Coupled Cars," Proceedings of the 1992 American Control Conference (Chicago, IL), June 1992, pp. 2053-2054.

${ }^{32}$ Schmitendorf, W. E., Dolphus, R. M., and Benson, R. W., "Quadratic Stabilization and Tracking: Applications to the Benchmark Problem," Proceedings of the 1992 American Control Conference (Chicago, IL), June 1992, pp. 2055-2058.

${ }^{33}$ Sznaier, M., and Rotstein, H., "Robust Controller Design for the Benchmark Problem Using a Mixed $l_{\infty} / H_{\infty}$ Approach," Proceedings of the 1992 American Control Conference (Chicago, IL), June 1992, pp. 2059-2060.

${ }^{34}$ Benson, D., and Schmidt, D., "The Benchmark Problem-Solutions via Classical Loop Shaping," 1992 American Control Conference (Chicago, IL), June 1992.

${ }^{35}$ Braatz, R. D., and Morari, M., "Robust Control for a Noncolocated Spring-Mass System," Proceedings of the 1992 American Control Conference (Chicago, IL), June 1992, pp. 2061-1062.

${ }^{36}$ Vinnicombe, G., "Robust Control Design in the Graph Topology-A Benchmark Design Example," Proceedings of the 1992 American Control Conference (Chicago, IL), June 1992, pp. 2063-2064.

${ }^{37}$ Sideris, A., and Rotstein, H., "Solution of Benchmark Control Problem by Constrained $H_{\infty}$ Optimization," Proceedings of the 1992 American Control Conference (Chicago, IL), June 1992, pp. 20652066.

${ }^{38}$ Wie, B., and Liu, Q., "Robust $H_{\infty}$ Control Design Solution to Benchmark Problem \#2," Proceedings of the 1992 American Control Conference (Chicago, IL), June 1992, pp. 2067-2068.

${ }^{39}$ Chiang, R. Y., and Safonov, M. G., "Real $k_{m}$-Synthesis via Generalized Popov Multipliers," Proceedings of the 1992 American Control Conference (Chicago, IL), June 1992, pp. 2417-2418.

${ }^{40}$ Hong, S., and Speyer, J. L., "Application of a Parameter Robust Game Theoretic Controller to the Benchmark Problem,"' Proceedings of the 1992 American Control Conference (Chicago, IL), June 1992, pp. 2419-2420.

${ }^{41}$ Stengel, R. F., and Marrison, C. I., "Stochastic Robustness Synthesis for a Benchmark Problem," Proceedings of the 1992 American Control Conference (Chicago, IL), June 1992, pp. 2421-2422.

${ }^{42}$ Sobhani, M., Jayasuriya, S., and Nwokah, O., "The Quantitative Feedback Design of the Benchmark Problem," Proceedings of the 1992 American Control Conference (Chicago, IL), June 1992, pp. 2423-2424.

${ }^{43}$ Collins, E. G., Haddad, W. M., and Bernstein, D. S., "Small Gain, Circle, Positivity, and Popov Analysis of a Maximum Entropy Controller for a Benchmark Problem," Proceedings of the 1992 American Control Conference (Chicago, IL), June 1992, pp. 24252426.

${ }^{44}$ Wie, B., and Liu, Q., "A Robust Feedforward/Feedback Approach to Benchmark Problem \#4" Proceedings of the 1992 American Control Conference (Chicago, IL), June 1992, pp. 2427-2428. 